\title{
Introduction to the special issue on tectonic environment and seabed resources of the southern Okinawa Trough
}

\author{
Song-Chuen Chen ${ }^{1}$, Jing-Yi Lin ${ }^{2,3, *}$, Chih-Chieh $\mathrm{Su}^{4}$, and Wen-Bin $\mathrm{Doo}^{3}$ \\ ${ }^{1}$ Central Geological Survey, Ministry of Economic Affairs, New Taipei City, Taiwan \\ ${ }^{2}$ Department of Earth Sciences, National Central University, Taoyuan City, Taiwan \\ ${ }^{3}$ Center for Environmental Studies, National Central University, Taoyuan City, Taiwan \\ ${ }^{4}$ Institute of Oceanography, National Taiwan University, Taipei City, Taiwan
}

Received 25 August 2019, Accepted 27 August 2019

Keywords: Southern Okinawa Trough, Hydrothermal system, Taiwan, Back-arc basin

Citation: Chen, S.-C., J.-Y. Lin, C.-C. Su, and W.-B. Doo, 2019: Introduction to the special issue on tectonic environment and seabed resources of the southern Okinawa Trough. Terr. Atmos. Ocean. Sci., 30, 605-611, doi: 10.3319/TAO.2019.08.27.01

Okinawa Trough (OT) is a back-arc basin behind the Ryukyu arc-trench system and located along the eastern margin of the Eurasian continent. It extends from the southwest Kyushu Island to the Ilan Plain of Taiwan (Fig. 1). The width and water depth vary from about $230 \mathrm{~km}$ and $200 \mathrm{~m}$ in its north to $60-100 \mathrm{~km}$ and $2300 \mathrm{~m}$ in its south (Sibuet et al. 1998). Based on geophysical and geological studies, the Okinawa Trough is considered to be in the rifting stage (Lee et al. 1980; Letouzey and Kimura 1986; Sibuet et al. 1987, 1998; Uyeda 1987; Kimura et al. 1988). Such a tectonic setting is characterized by active normal faulting in its upper crust and numerous intrusions of magma. Hence, the OT is expected to have a favorable environment for the development of a hydrothermal system. Recently, diverse microbial communities and other hydrothermal minerals have been discovered in the middle and northern Okinawa Trough (Uyeda 1987; Kimura et al. 1988; Halbach et al. 1989; Sakai et al. 1990; Glasby and Notsu 2003; Lüders and Niedermann 2010; Ishibashi et al. 2014; Toki et al. 2016; Minami and Ohara 2017). The southern OT is close to Taiwan and topographically has the lowermost trough throughout the Okinawa Trough (Fig. 1), suggesting a pronounced back-arc basin. However, restricted by the limited sampling and sequencing studies, our understanding of its marine environment and hydrothermal potential is poor. Supported by Central Geological Survey (CGS), Ministry of Economic Affairs (MOEA) of Taiwan, a 4-year program entitled "Geological Investigation of Mineral Resource Potential in the Offshore Area of Northeastern Taiwan" was launched in 2016. Significant contributions have been made in understanding the origin, distribution, and characteristics of hydrothermal deposits in the southern Okinawa Trough.

\footnotetext{
* Corresponding author

E-mail:jylin@ncu.edu.tw
}

Integration of geological, geophysical, geochemical and seafloor observation studies of the background environment is very helpful for understanding the hydrothermal mineral deposits in the southern OT.

The beginning of the Okinawa Trough back-arc rifting is suggested to be in Late Miocene (Hirata et al. 1991; Miki 1995; Shinjo et al. 1999; Chung et al. 2000; Shinjo and Kato 2000). The earliest opening, probably associated with the formation of the Japan Sea, may start in the middle and northern OT between 10 - 6 Ma (Sibuet et al. 1987; Miki 1995; Shinjo et al. 1999). Together with the clockwise rotation of the southernmost Ryukyu Arc, the southern OT started to open in Plesistocene ( 2 Ma) (Miki 1995; Park et al. 1998; Shinjo et al. 1999). Based on seismic data, Sibuet et al. (1998) suggested two last extensional phases in the SOT: a rifting along $\mathrm{N} 150^{\circ}$ during Pleistocene $(2-0.1 \mathrm{Ma})$ and one along $\mathrm{N} 170^{\circ}$ during late Pleistocene-Holocene (0.1 - $\left.0 \mathrm{Ma}\right)$, respectively. Active rifting structures and extrusion or intrusion of magma display the most pronounced tectonic features in the SOT. The excessive magma supply and the extensional normal faults provide thermal sources and conduits, which facilitate the hydrothermal fluid circulation. The multi-beam bathymetric and seismic data in the southern OT indicate the presence of more than 70 submarine volcanos in the SOT. Although several volcanic structures have been recognized in the previous investigation (Sibuet et al. 1998; Tsai 1999; Lee et al.2004), a lack of a consistent name for those structures makes it difficult for discussions in related studies. In this special issue, we group and label the major structures on the basis of their geological characteristics, which provides a more systemically idea about the geological structures in the SOT (Fig. 2). Yunaguni Knoll IV-1 (YK4-1) is the first reported hydrothermal site in the SOT. It is characterized by massive sulfide deposits, sulfide chimney, active black smoker and extremely high heat flow (Inagaki et al. 2006; 


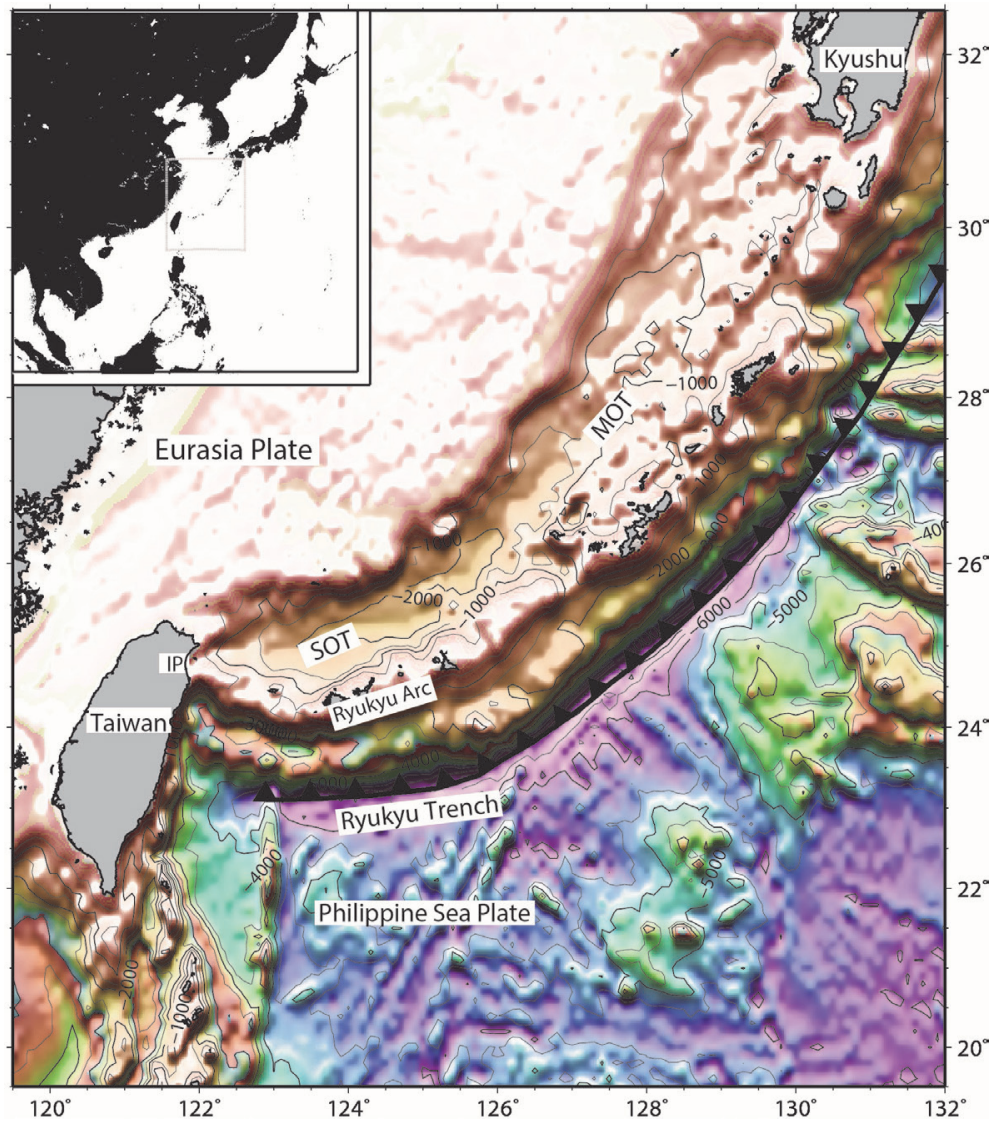

Fig. 1. Tectonic setting of the Ryukyu subduction and the Okinawa Trough system. SOT and MOT indicate the southern and middle Okinawa Trough; IP shows the Ilan Plain.

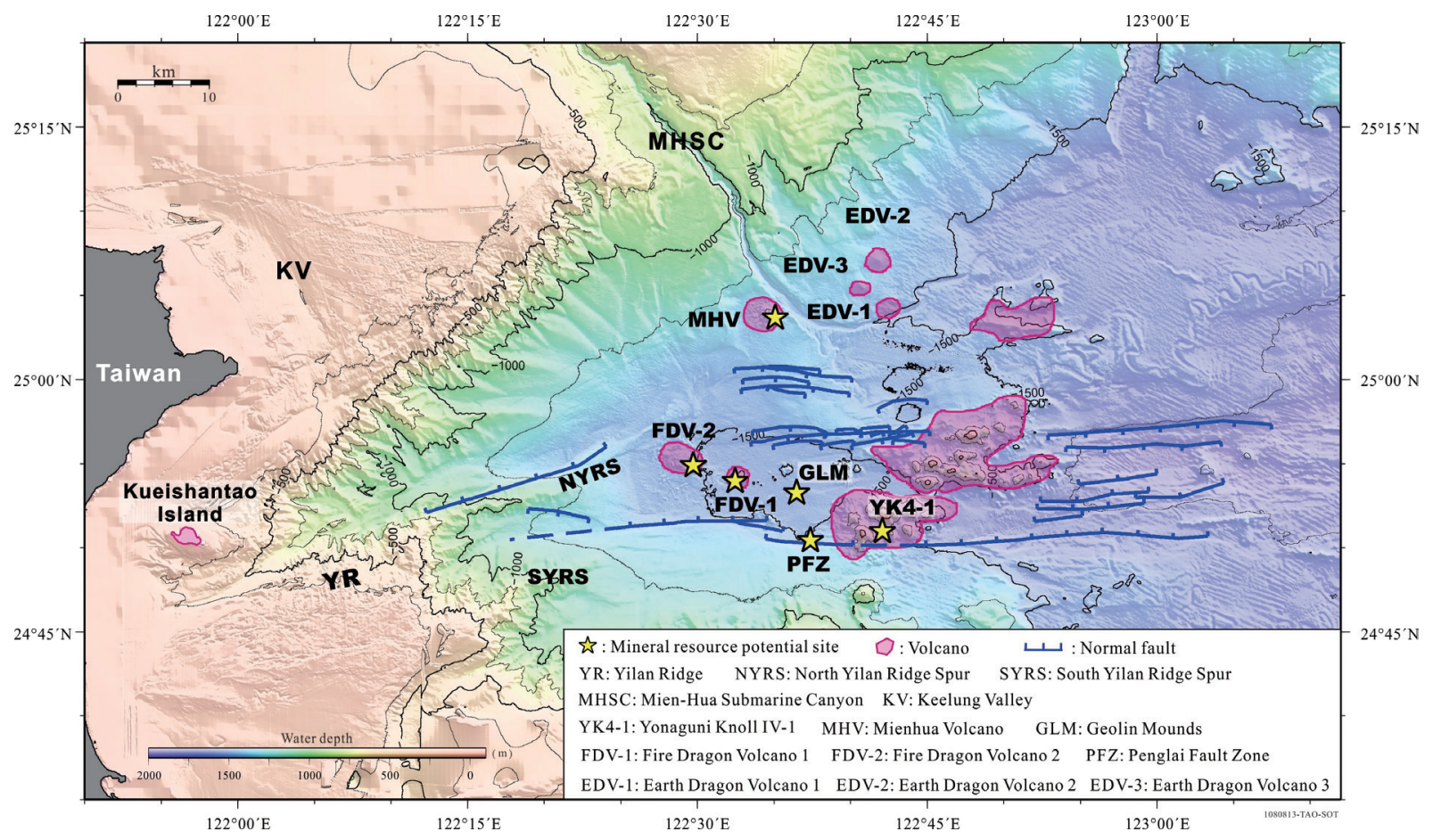

Fig. 2. Bathymetry and geological structures in the southern Okinawa Trough. The main normal faults and mineral potential sites are indicated by blue lines and yellow stars, respectively. 
Suzuki et al. 2008; Nunoura et al. 2010; Gena et al. 2013; Ishibashi et al. 2015), which shows a high hydrothermal potential site. Fire Dragon volcanic group, including Fire Dragon Volcano 1 (FDV-1) and Fire Dragon Volcano 2 (FDV-2), represents the submarine volcanos with significant volcanic morphology, which can be well identified by the seafloor morphology. This type of volcanos is generally located in the central axis. However, the Mienhua Volcano (MHV) is situated at the foot of the Mein-Hua Submarine Canyon (MHSC) and may be related to post-collisional volcanoes in northern Taiwan (Wang et al. 1999). The volcanos without outcrops on the seafloor are defined as Earth Dragon volcanic group, which comprises Earth Dragon Volcano 1 (EDV1), Earth Dragon Volcano 2 (EDV-2), and Earth Dragon Volcano 3 (EDV-3). All these volcanos are located at the continental slope, to the northeast of the MHSC. Two potential hydrothermal sites without volcano-like shape have also been identified in the SOT, the Geolin Mounds (GLM) and the Penglai Fault zone (PFZ) (Hsu 2017). The two sites are discovered during the implementation of the "Geological Investigation of Mineral Resource Potential in the Offshore Area of Northeastern Taiwan" project, supported by CGS. Offshore northeastern Taiwan, the seafloor displays three particular features of bathymetry: the Yilan Ridge (YR), the North Yilan Ridge Spur (NYRS), and the South Yilan Ridge Spur (SYRS). However, few volcanic bodies were reported around this area.

Being aware of the importance of enquiring the related tectonic and environmental processes for the generation of hydrothermal mineral resources and its possible impact on the surrounding microbial communities, this special issue has collected 9 papers, mainly addressing the tectonic environment and seabed resources of the southern OT.

First of all, the formation and evolution of hydrothermal fields are largely affected by magma activities, which are deeply associated with the regional tectonics, i.e., the subduction and back-arc rifting. Lo et al. (2019) has documented the crustal stress field of the southernmost end of the Okinawa Trough, the Ilan Plain (IP), by using the focal mechanisms shallower than $15 \mathrm{~km}$ during the period 1996 - 2016. They show that the dominant stress regime in that region is of extension and the E-W trending axis of the IP, cutting through the plain, plays the role of a distinctive stress boundary. The $\sigma_{3}$ is along the NW-SE direction in the north, but changes to N-S in the south. Nevertheless, the distribution of $\sigma_{1}$ is relatively complex. Although the $\sigma_{1}$ is consistent in N-S direction off IP, the directions are uncertain but mainly along the NW-SE and NE-SW in the northern and southern part of the IP, respectively. Their result infers that the opening process of the SOT is undergoing in its western end and could be affected by the inland geological structures.

The submarine volcanos are generally considered as an indicator for the presence of a hydrothermal system. Howev- er, dominated by the complex extensional faults in the SOT, the volcanos locations may not be the direct response of the heat supply from the source below the seafloor. To study the distribution of low frequency (LF) volcanic events, Lin et al. (2019a) examined the waveforms of 2263 earthquakes collected by the inland Central Weather Bureau Seismic Network (CWBSN) stations between 1991 and 2011. The LF earthquakes are regarded worldwide as an indication of the motion of magmatic fluid at great depths. They found $80 \mathrm{LF}$ earthquakes and compared the hypocenters with an updated relocation seismicity catalog to obtain more reliable epicenter locations. Their results show that the LF events were mainly located along the central axis of the SOT or to the southeast of the Kueishantao (KST) Island. The depths of the LF events change from about $15 \mathrm{~km}$ near KST to $20 \mathrm{~km}$ along the central axis of the SOT. Additionally, the LF earthquake clusters near the KST show a spatial migration over a span of 4 years. The distribution of LF earthquakes shows that the hydrothermal sites of the SOT system should be located near its central axis or near the KST. Besides heat source supplies, host rock composition is also crucial for the hydrothermal alteration in the submarine mineral system. To analyze this aspect, Lin et al. (2019b) analyzed the mineral resource potential based on the geochemical characters of the cored sediment pore-water. They quantified that the sedimentary carbon remineralization rate in SOT is $1.68 \pm 0.21 \mathrm{mmol} \mathrm{C} \mathrm{m}^{-2} \mathrm{~d}^{-1}$ in the upper $30 \mathrm{~cm}$ sediment column, which is 10 times lower than the East China Sea area. This descend remineralization rate was attributed to the lower bottom-water temperature and carbon flux in the SOT. In addition, a high carbon burial efficiency of $68 \%$ also infers the combined effects of small rivers and riftinginduced particle trapping processes. On the other hand, extremely high $\mathrm{Fe}^{2+}$ concentrations (up to $450 \mu \mathrm{mol} \mathrm{L}^{-1}$ ) in the pore-water were observed, which indicates the incorporation of hydrothermally derived reactive $\mathrm{Fe}$ into sediments. Finally, all the observations lead to the conclusion that the general diagenetic condition is the main factor controlling the sediment composition with a slight affection from the hydrothermal activities.

Bearing all the background information in mind, the discovery of the potential hydrothermal sites relies on the use of marine geophysical and geochemical methods. In hydrothermal circulation sites, hot water brings volcanic materials through the conduits, known as a "black smoker", forming a smoky zone (Baker et al. 1995). This venting black smoker emits jets of particle-laden fluids to the water column, which could be detected by echo-sounder water-column imaging technology. In this special issue, Tsai et al. (2019) analyzed the $38 \mathrm{kHz}$ single-beam echo sounder (EK60) acquired from 13 surveys and recognized 266 gas plume acoustic images, which are probably associated with the SOT hydrothermal circulation system. The distribution of the gas plumes is an important indicator for 
the hydrothermal sites. In addition, they further used the images to estimate the bottom current speeds, which vary from $2-160 \mathrm{~cm} \mathrm{~s}^{-1}$ in volcanic area to $20-50 \mathrm{~cm} \mathrm{~s}^{-1}$ in relatively flat area. Their results also indicate a periodic variation of bottom current direction linked to the semi-diurnal tide. On the other hand, active venting hydrothermal sites are often characterized by high heat flow and specifically geochemical features with high metal element content. Both factors should influence the magnetic field. Doo et al. (2019) extracted short-wavelength magnetic signals from a deeptowed magnetic survey to study the shallow subsurface structures of hydrothermal systems. Assume a magnetized layer with a constant thickness of $500 \mathrm{~m}$ and seafloor as the top surface, the crustal magnetization map could actually reflect the magnetic characteristics of subsurface materials. Compared with the gas plumes distribution and other geochemical/geophysical observation, several low magnetic anomalous zones, i.e., GLM and PFZ, are suggested to have high hydrothermal potential. Except for the magnetic data acquired from a larger scale survey, the magnetic susceptibility measured from sediment cores can also provide magnetic signatures for the hydrothermal system. Huang et al. (2019) analyzed the marine sediment cores obtained near the YK4-1 hydrothermal site. They found that the core samples extracted from the sites with no gas disturbance expose a stable magnetic susceptibility of about between $20 \times$ $10^{-5}$ and $60 \times 10^{-5} \mathrm{SI}$, which is close to the background value of the SOT. However, the magnetic susceptibility from the sediment cores affected by gas activities could have large variation. They suggest that authigenic iron sulfides associated with the hydrothermal alteration could be the main cause for the abrupt change of the susceptibility. Regarding to hydrothermal alteration, fluid flow in porous rocks is one of the main mechanisms to transport minerals from the lower crust into upper crust of the Earth. In order to understand the fluid flow pattern in a hydrothermal field, Wu et al. (2019) use in-situ 4 temperature profiles data and apply 1-D- "Péclet number analysis" and 3-D numerical modeling methods to estimate the fluid flow rate in the YK4-1. The objective is to understand the physics behind the fluid flow rate and in-situ temperature observations. Their results show that the fluid migration rates are about 84 and $117 \mathrm{~m} \mathrm{yr}^{-1}$ based on the 1-D and 3-D modeling methods, respectively. Importing the parameters of $30 \mathrm{~cm}$ as fissure diameter and $1.025 \mathrm{~g} \mathrm{~cm}^{-3}$ as fluid density, the 3-D modeling can also derive a flux-emitting rate at site of about $0.27 \mathrm{~g} \mathrm{~s}^{-1}$, which offers a quantitative estimation for the fluid migration.

For the investigation of the hydrothermal systems near Taiwan, the most stunning thing could be the discovery of the unconventional hydrothermal sites of GLM and PFZ. No obvious submarine volcanos are associated with those two sites, but only with numerous morphological mounts of several to tens of meters (Hsu 2017). The finding of those two sites was mainly accomplished by deep-towed side- scan sonars (Hsu 2017). Acoustically blanking zone in the shallow sediments was also imaged by sub-bottom profilers. The water columns above these two sites contain several gas flares (plumes) that may reach the sea surface. To further understand the nature of these two sites, Hsu et al. (2019) performed a pseudo-3D processing to the multi-channel seismic (MCS) surveys data conducted in 2018 and create a pseudo-3D seismic image of the GLM. The seismic cube allows a better determination of fault structures and provides estimation of blanking zones on selected time slice. They also suggested that GLM is in its embryo stage of evolution for its hydrothermal system, which can explain why no submarine volcanos were found on the seafloor. Furthermore, the obvious blanking zone determined from the seismic data infers also constantly the vigorous subsurface hydrothermal circulation. They suggested that extensive studies in the GLM could be helpful for understanding the development of the seafloor edifice and ore mineralization associated with hydrothermal circulation activities.

For the exploration of marine mineral resources, it is very important to develop independent observational research capabilities. In this special issue, Chou et al. (2019) introduced the new-developed deep-towed vehicles and seafloor survey results obtained in 2016 and 2017 to demonstrate the instrument ability and the seafloor characteristics in the SOT. Their instrument includes 4 main components, the Abyss Twist-pair Imaging System (ATIS), the Videoguided Multi-corer (V-Corer), the TV-guided Grabber (TVG), and the Fiber-optical Instrumentation Towed System (FITS), which allows real-time visual observation for the seafloor. Several videos, samples of animals, sediments, and mounds, have been acquired and analyzed for various research proposes. In their paper, the video data are crosschecked and various of seafloor features are classified. Biological communities, including deep-sea mussels and squat lobsters, are the most popular aspect which can be observed for all the hydrothermal sites. The presence of bubble phenomenon and active hydrothermal chimneys provide the direct evidence about the hydrothermal potential in the SOT.

Through the collection of the papers in this issue, we wish to promote our understanding of hydrothermal system in the SOT and to stimulate more multidisciplinary researches on hydrothermal potential in Taiwan. All the efforts cannot only provide an opportunity for the discussion of research results, but also emphasize the support from the government for the study on the marine sciences.

Acknowledgements We dedicate this special issue to the Central Geological Survey (CGS), Ministry of Economic Affairs (MOEA) in Taiwan. CGS financially supported the marine mineral resource program and provided enormous help for the implementation of the 4-years project in the SOT. We wish to thank all the authors who contributed to this special issue and we express our gratitude to all the 
reviewers who provided thorough and insightful comments on the manuscripts.

\section{REFERENCES}

Baker, E. T., C. R. German, and H. Elderfield, 1995: Hydrothermal plumes over spreading-center axes: Global distributions and geological inferences. In: Humphris, S. E., R. A. Zierenberg, L. S. Mullineaux, and R. E. Thomson (Eds.), Seafloor Hydrothermal Systems: Physical, Chemical, Biological, and Geological Interactions, Volume 91, American Geophysical Union, 4771, doi: 10.1029/GM091p0047. [Link]

Chou, Y.-C., C.-C. Wang, H.-H. Chen, and Y.-H. Lin, 2019: Seafloor characterization in the southernmost Okinawa Trough from underwater optical imagery. Terr. Atmos. Ocean. Sci., 30, 717-737, doi: 10.3319/ TAO.2019.03.14.01. [Link]

Chung, S.-L., S.-L. Wang, R. Shinjo, C.-S. Lee, and C.-H. Chen, 2000: Initiation of arc magmatism in an embryonic continental rifting zone of the southernmost part of Okinawa Trough. Terr. Nova, 12, 225-230, doi: 10.1046/j.1365-3121.2000.00298.x. [Link]

Doo, W.-B., S.-K. Hsu, H.-F. Wang, Y.-S. Huang, C.-H. Tsai, C.-L. Lo, S.-S. Lin, C.-W. Liang, and Y.-J. Lin, 2019: A deep-towed magnetic survey in the southern Okinawa Trough: Implications for hydrothermal system detection. Terr. Atmos. Ocean. Sci., 30, 675-683, doi: 10.3319/TAO.2019.02.15.01. [Link]

Gena, K., H. Chiba, K. Kase, K. Nakashima, and D. Ishiyama, 2013: The Tiger Sulfide Chimney, Yonaguni Knoll IV Hydrothermal Field, Southern Okinawa Trough, Japan: The First Reported Occurrence of Pt-Cu-Fe-Bearing Bismuthinite and Sn-Bearing Chalcopyrite in an Active Seafloor Hydrothermal System. Resour. Geol., 63, 360-370, doi: 10.1111/rge.12015. [Link]

Glasby, G. P. and K. Notsu, 2003: Submarine hydrothermal mineralization in the Okinawa Trough, SW of Japan: An overview. Ore Geol. Rev., 23, 299-339, doi: 10.1016/j.oregeorev.2003.07.001. [Link]

Halbach, P., K. Nakamura, M. Wahsner, J. Lange, H. Sakai, L. Käselitz, R.-D. Hansen, M. Yamano, J. Post, B. Prause, R. Seifert, W. Michaelis, F. Teichmann, M. Kinoshita, A. Märten, J. Ishibashi, S. Czerwinski, and N. Blum, 1989: Probable modern analogue of Kuroko-type massive sulphide deposits in the Okinawa Trough back-arc basin. Nature, 338, 496-499, doi: 10.1038/338496a0. [Link]

Hirata, N., H. Kinoshita, H. Katao, H. Baba, Y. Kaiho, S. Koresawa, Y. Ono, and K. Hayashi, 1991: Report on DELP 1988 cruises in the Okinawa Trough: Part 3. Crustal structure of the southern Okinawa Trough. Bull. Earthq. Res. Inst. Univ. Tokyo, 66, 37-70.

Hsu, H.-H., L.-F. Lin, C.-S. Liu, J.-H. Chang, W.-Z. Liao,
T.-T. Chen, K.-H. Chao, S.-L. Lin, H.-S. Hsieh, and S.C. Chen, 2019: Pseudo-3D seismic imaging of Geolin Mounds hydrothermal field in the Southern Okinawa Trough offshore NE Taiwan. Terr. Atmos. Ocean. Sci., 30, 705-716, doi: 10.3319/TAO.2019.03.14.02. [Link] Hsu, S.-K., 2017: Geological Investigation of Mineral Resource Potential in the Offshore Area of Northeastern Taiwan: High Resolution Sonar and Magnetic Surveys (2/4). Report of Central Geological Survey, 106-13, 237 pp. (in Chinese with English abstract)

Huang, Y.-S., C.-C. Su, W.-B. Doo, S.-K. Hsu, C.-H. Tsai, H.-F. Wang, S.-S. Lin, C.-W. Liang, J.-Y. Lin, J.-E. Chen, Y.-J. Lin, and Y. Wang, 2019: Hydrothermal activity revealed by rock magnetic anomaly from core sediments in the southern Okinawa Trough. Terr. Atmos. Ocean. Sci., 30, 685-694, doi: 10.3319/ TAO.2019.07.31.01. [Link]

Inagaki, F., M. M. M. Kuypers, U. Tsunogai, J. Ishibashi, K. Nakamura, T. Treude, S. Ohkubo, M. Nakaseama, K. Gena, H. Chiba, H. Hirayama, T. Nunoura, K. Takai, B. B. Jorgensen, K. Horikoshi, and A. Boetius, 2006: Microbial community in a sediment-hosted $\mathrm{CO}_{2}$ lake of the southern Okinawa Trough hydrothermal system. Proc. Natl. Acad. Sci., 103, 14164-14169, doi: 10.1073/pnas.0606083103. [Link]

Ishibashi, J.-I., T. Noguchi, T. Toki, S. Miyabe, S. Yamagami, Y. Onishi, T. Yamanaka, Y. Yokoyama, E. Omori, Y. Takahashi, K. Hatada, Y. Nakaguchi, M. Yoshizaki, U. Konno, T. Shibuya, K. Takai, F. Inagaki, and S. Kawagucci, 2014: Diversity of fluid geochemistry affected by processes during fluid upwelling in active hydrothermal fields in the Izena Hole, the middle Okinawa Trough back-arc basin. Geochem. J., 48, 357369, doi: 10.2343/geochemj.2.0311. [Link]

Ishibashi, J.-I., F. Ikegami, T. Tsuji, and T. Urabe, 2015: Hydrothermal activity in the Okinawa Trough back-arc basin: Geological background and hydrothermal mineralization. In: Ishibashi, J.-I., K. Okino, and M. Sunamura (Eds.), Subseafloor Biosphere Linked to Hydrothermal Systems, Springer, Tokyo, 337-359, doi: 10.1007/978-4-431-54865-2_27. [Link]

Kimura, M., S. Uyeda, Y. Kato, T. Tanaka, M. Yamano, T. Gamo, H. Sakai, S. Kato, E. Izawa, and T. Oomori, 1988: Active hydrothermal mounds in the Okinawa Trough backarc basin, Japan. Tectonophysics, 145, 319-324, doi: 10.1016/0040-1951(88)90203-X. [Link]

Lee, C.-S., G. G. Shor, L. D. Bibee, R. S. Lu, and T. W. C. Hilde, 1980: Okinawa Trough: Origin of a back-arc basin. Mar. Geol., 35, 219-241, doi: 10.1016/00253227(80)90032-8. [Link]

Lee, Y., C. Tsai, and C. Lee, 2004: The study of active submarine volcanoes and hydrothermal vents in the southernmost part of Okinawa Trough. American Geophysical Union, Fall Meeting 2004, abstract id. S41 A-0939. 
Letouzey, J. and M. Kimura, 1986: The Okinawa Trough: Genesis of a back-arc basin developing along a continental margin. Tectonophysics, 125, 209-230, doi: 10.1016/0040-1951(86)90015-6. [Link]

Lin, J.-Y., W.-N. Wu, C.-C. Su, C.-H. Tsai, H.-H. Sun, Y.-F. Chen, S.-J. Chin, and Y.-C. Lin, 2019a: Spatial and temporal distribution of low frequency volcanic earthquakes in the southern Okinawa Trough backarc basin. Terr. Atmos. Ocean. Sci., 30, 621-631, doi: 10.3319/TAO.2018.12.24.01. [Link]

Lin, Y.-S., H.-T. Lin, B.-S. Wang, S.-F. Wu, P.-L. Wang, C.-L. Wei, H.-F. Lee, T. Lan, W.-J. Huang, S.-C. Chen, Y. Wang, and C.-C. Su, 2019b: Early diagenesis and carbon remineralization in young rift sediment of the Southern Okinawa Trough. Terr. Atmos. Ocean. Sci., 30, 633-647, doi: 10.3319/TAO.2019.01.10.01. [Link]

Lo, C.-L., W.-N. Wu, W.-B. Doo, Y.-S. Huang, and S.-K. Hsu, 2019: Crustal stress field in Ilan Plain, NE Taiwan and the westernmost Okinawa trough-deduced from seismic stress inversion. Terr. Atmos. Ocean. Sci., 30, 613-619, doi: 10.3319/TAO.2019.08.09.01. [Link]

Lüders, V. and S. Niedermann, 2010: Helium isotope composition of fluid inclusions hosted in massive sulfides from modern submarine hydrothermal systems. Econ. Geol., 105, 443-449, doi: 10.2113/gsecongeo.105.2.443. [Link]

Miki, M., 1995: Two-phase opening model for the Okinawa Trough inferred from paleomagnetic study of the Ryukyu arc. J. Geophys. Res., 100, 8169-8184, doi: 10.1029/95JB00034. [Link]

Minami, H. and Y. Ohara, 2017: The Gondou hydrothermal field in the Ryukyu Arc: A huge hydrothermal system on the flank of a caldera volcano. Geochem. Geophys. Geosyst., 18,3489-3516, doi: 10.1002/2017GC006868. [Link]

Nunoura, T., H. Oida, M. Nakaseama, A. Kosaka, S. B. Ohkubo, T. Kikuchi, H. Kazama, S. Hosoi-Tanabe, K. Nakamura, M. Kinoshita, H. Hirayama, F. Inagaki, U. Tsunogai, J. Ishibashi, and K. Takai, 2010: Archaeal diversity and distribution along thermal and geochemical gradients in hydrothermal sediments at the Yonaguni Knoll IV hydrothermal field in the Southern Okinawa Trough. Appl. Environ. Microbiol., 76, 11981211, doi: 10.1128/AEM.00924-09. [Link]

Park, J.-O., H. Tokuyama, M. Shinohara, K. Suyehiro, and A. Taira, 1998: Seismic record of tectonic evolution and backarc rifting in the southern Ryukyu island arc system. Tectonophysics, 294, 21-42, doi: 10.1016/ S0040-1951(98)00150-4. [Link]

Sakai, H., T. Gamo, E.-S. Kim, M. Tsutsumi, T. Tanaka, J. Ishibashi, H. Wakita, M. Yamano, and T. Oomori, 1990: Venting of carbon dioxide-rich fluid and hydrate formation in mid-Okinawa trough backarc basin. Science, $\mathbf{2 4 8}$,
1093-1096, doi: 10.1126/science.248.4959.1093. [Link]

Shinjo, R. and Y. Kato, 2000: Geochemical constraints on the origin of bimodal magmatism at the Okinawa Trough, an incipient back-arc basin. Lithos, 54, 117 137, doi: 10.1016/S0024-4937(00)00034-7. [Link]

Shinjo, R., S.-L. Chung, Y. Kato, and M. Kimura, 1999: Geochemical and $\mathrm{Sr}-\mathrm{Nd}$ isotopic characteristics of volcanic rocks from the Okinawa Trough and Ryukyu Arc: Implications for the evolution of a young, intracontinental back arc basin. J. Geophys. Res., 104, 10591-10608, doi: 10.1029/1999JB900040. [Link]

Sibuet, J.-C., J. Letouzey, F. Barbier, J. Charvet, J.-P. Foucher, T. W. C. Hilde, M. Kimura, L.-Y. Chiao, B. Marsset, C. Muller, and J.-F. Stéphan, 1987: Back arc extension in the Okinawa Trough.J. Geophys. Res., 92, 14041-14063, doi: 10.1029/JB092iB13p14041. [Link]

Sibuet, J.-C., B. Deffontaines, S.-K. Hsu, N. Thareau, J.P. Le Formal, and C.-S. Liu, 1998: Okinawa trough backarc basin: Early tectonic and magmatic evolution. J. Geophys. Res., 103, 30245-30267, doi: 10.1029/98JB01823. [Link]

Suzuki, R., J.-I. Ishibashi, M. Nakaseama, U. Konno, U. Tsunogai, K. Gena, and H. Chiba, 2008: Diverse Range of Mineralization Induced by Phase Separation of Hydrothermal Fluid: Case Study of the Yonaguni Knoll IV Hydrothermal Field in the Okinawa Trough Back-Arc Basin. Resour. Geol., 58, 267-288, doi: 10.1111/j.1751-3928.2008.00061.x. [Link]

Toki, T., M. Itoh, D. Iwata, S. Ohshima, R. Shinjo, J. Ishibashi, U. Tsunogai, N. Takahata, Y. Sano, T. Yamanaka, A. Ijiri, N. Okabe, T. Gamo, Y. Muramatsu, Y. Ueno, S. Kawagucci, and K. Takai, 2016: Geochemical characteristics of hydrothermal fluids at Hatoma Knoll in the southern Okinawa Trough. Geochem. J., 50, 493-525, doi: 10.2343/geochemj.2.0449. [Link]

Tsai, C.-H., 1999: Submarine volcanoes and hydrothermal circulation in the Southernmost Part of Okinawa Trough: An Initial Study. Master Thesis, National Taiwan Ocean University, Keelung City, Taiwan, 92 pp. (in Chinese with English abstract)

Tsai, C.-H., S.-K. Hsu, Y.-F. Chen, H.-S. Lin, S.-Y. Wang, S.-C. Chen, C.-W. Liang, and Y.-Y. Cho, 2019: Gas plumes and near-seafloor bottom current speeds of the southernmost Okinawa Trough determined from echo sounders. Terr. Atmos. Ocean. Sci., 30, 649-674, doi: 10.3319/TAO.2019.07.07.01. [Link]

Uyeda, S., 1987: Active hydrothermal mounds in the Okinawa back-arc trough. Eos, Trans. AGU, 68, 737, doi: 10.1029/EO068i036p00737-01. [Link]

Wang, K.-L., S.-L. Chung, C.-H. Chen, R. Shinjo, T. F. Yang, and C.-H. Chen, 1999: Post-collisional magmatism around northern Taiwan and its relation with opening of the Okinawa Trough. Tectonophysics, 308, 
363-376, doi: 10.1016/S0040-1951(99)00111-0. [Link] Wu, T.-W., W.-C. Chi, Y.-S. Lin, and S.-C. Chen, 2019: Temperature as a tracer for fluid movement at hydro- thermal sites near the Yonaguni Knoll IV, Okinawa Trough. Terr. Atmos. Ocean. Sci., 30, 695-704, doi: 10.3319/TAO.2019.01.10.02. [Link] 